\title{
UEBER DIE QUELLEN
}

\author{
DER ITALIENISCHEN
}

\section{REFORMATIONSGESCHICHTE.}

\author{
Antrittsrede \\ gehalten am 1. Juli 1876 \\ in der Aula der Rheinischen Friedrich-Wilhelms-Universität \\ von
}

Lic. Dr. KARL BENRATH

PRIVATDOCENT DER THEOLOGIE.

BONN

BEI ADOLPH MARCUS.

1876. 
